\title{
EXPLORING TOURIST PERCEPTIONS ON BUDDHIST TEMPLE STAY PROGRAMS IN SRI LANKA
}

\author{
A. R. N. T. Jayasinghe \\ Sri Lanka Institute of Tourism and Hotel Management, Colombo, Sri Lanka
}

Article DOI: https://doi.org/10.36713/epra7823

DOI No: 10.36713/epra7823

\begin{abstract}
Temple stay program is a newly formed but comparably mature religious and cultural tourism product in Sri Lanka that accommodates and caters to tourists in Buddhist temples and allows them to experience Theravada Buddhist traditions and culture. Through, temple stay program turns out to be a distinctive phenomenon which successfully establishes a unique identity of Buddhist culture and tourism, as well as expand the influence of Theravada Buddhism. However, the respective authorities have paid a little attention to religious and cultural purposes when visiting Sri Lanka by tourist. As a result, the main issue for this study stems from this scenario. Sri Lanka is researching and trying to launch new products, including Buddhist temple stay program, for the Sri Lankan tourism industry to attract more tourists who will benefit to tourism development. Education of Buddhist philosophy, spiritual development, develop self confidence, develop psychological strength and culture of Sri Lanka are main areas covered by temple stay program in Sri Lanka. This study is aim to gain and understanding on the current tourist perception on temple stay program in Sri Lanka. The main objectives of this study are: a) to identify the current behavioral pattern of tourist who engaged with temple stay programs in Sri Lanka; 2) to examine tourist perception on Buddhist temple stay programs in Sri Lanka as a concept of tourism development; 3) to identify the challenges facing by tourist while engage with Buddhist temple stay programs in Sri Lanka. This study conducted using structured questionnaire to collect primary data with 80 local and foreign tourist who engaged with temple stay programs in Kandy, Gampaha and Badulla district in Sri Lanka. The major source for information was the qualitative tool of in-depth interviews with tourists. Secondary data sources such as previous studies were the most significant used in this study; books, journals, reports, magazines and online data sources. The simple statistical analyses like demographic details and other patterns can be performed using the MS Excel software. The results of this study indicate that there is a positive tourist perception about temple stay programs in Sri Lanka. The respective authorities need to be identify the lacking areas and in order to develop strategies to maintain standards and improve temple stay programs in Sri Lanka.
\end{abstract}

KEYWORDS: Temple stay program,Buddhist tourism, Spiritual tourism, Tourism industry

\subsection{INTRODUCTION}

Buddhism is one of the most important philosophies influencing Indian philosophy and its way of life. Some believe it is a branch of Hinduism. Buddhism was born in India and spread throughout the world, especially in Asia. Buddhists all over the world view India with great respect and admiration. They consider Buddhist sites to be the main attraction to visit.

Buddhist tourism is a form of tourism that can promote peace and harmony in the world. Buddhist tourism is also a sustainable tourism that can create a link between local communities in tourist objects and tourists through tourism activities that focus on awareness of tourism experiences. Tourists will touch and admire the great power of faith that is presented in the magnificent and unique architecture of religious landmarks, beautiful local culture presented in a ritual that blends religion and local culture into the unique religion of the area, historical knowledge that tourists will learn from archaeological sites and objects, including local beliefs, traditions and ways of life. It is estimated that Buddhist tourism trends will continue to increase in the future, increasing to 600 million foreign tourists, $50 \%$ of whom are Asian (Mihir Bhonsale, 2019). This sustainable growth will be focused on Buddhist tourist attractions in South Asia, the beginnings of Buddhism, and in Southeast Asia, the prosperity of Buddhism (Puvaneswary, S, 2019). The growth of Buddhist tourists can generate tremendous income that spreads to the economy of local tourist attractions, creates local jobs and understands social balance, and respects the human rights of people in tourist attractions (Qin, YH, 1998). 


\subsection{Buddhist Tourism in Sri Lanka}

Sri Lanka is also a country that prioritizes the promotion of Buddhist tourism and is presented as an important religious site which is the official site of Buddhism. These important religious sites are as follows: Anuradhapura, where the holy city of Anuradhapura is located, Dambula, where the cave temple Rangiri Dambula is located, and Kandy, where the holy city of Kandy is located. All three holy cities have been declared World Heritage Sites, including the city of Polonnaruwa. In addition, there are cities in Sri Lanka which are believed to be holy places because they are places visited by the Buddha. According to the history, the places visited by the Buddha included Sri Padaya, Mahianganaya, Nagadepaya and Kelania. As Buddhist tourist attractions are full and tourism benefits generated US $\$ 4,380.6$ million in revenue for the country's economic system in 2018 (SLTDA, 2019),they helped Sri Lanka set a Goal to promote tourism in Buddhism.

Buddhist tourism in Sri Lanka includes meditation, yoga, archaeological travel, history and pilgrimages, as well as training in Buddhist philosophy. There are many places that have been identified with the help of the tourism of Sri Lanka, that can provide to the tourists who are in seeking of the realities of life. Therefore, there are hundreds of monks in and around Kandy where positioned is Sri Dalada Maligawa or the Tooth Temple, where the Buddha's sacred teeth are located. In fact, there are 6,000 Buddhist monasteries in Sri Lanka with around 15,000 monks. Therefore, when the sun rises, tourists will hear chanting of pirith coming from all the directionsin Sri Lanka.

\subsection{Temple Stay Programs in Sri Lanka}

The temple stay program defined here is somewhat different from "stay temple." While "temple stay" means a night at the temple, sometimes with optional services, the "temple stay program" in this document specifically refers to a comprehensive religious and cultural program initiated by management of temple. The Temple Stay program is a unique cultural program that allows people to live the life of a Buddhist practitioner in a traditional temple preserving 2,500 years of Buddhist history and Theravada culture. The temple still offers a wide variety of practice methods such as meditation, yoga, Buddhist philosophy and communal Buddhist meal service for healthy life

Meditation is a main program of the temple stay programs in Sri Lanka. Buddhist mediation practices are structures that energize and create focus, clearness, enthusiastic energy, and a quiet looking at of the real notion of things. By engaging with a specific meditation exercise people analyze the patterns and habits of their mind,and the practice a skill to cultivate new,more positive methods of being.Buddhist meditation consists of a range of meditation techniques that purpose to develop sati (mindfulness), samadhi (concentration), abhijñā (supramundane

powers), samatha (tranquility), vipassanā (insight) and Metta. Therefore, meditation centres are increasing day by day within the country. But there is lack of support and non-regulatory frame work for development.Beside of the meditation program, temples conduct various types of activities for people who are stay in temple for short time or long time period. Such as, Bodhi pooja, Dhamma discussion, Charity services, awareness program and etc.

Table 1.0 Day Programs at Temple for Tourist

\begin{tabular}{|l|l|}
\hline \multicolumn{1}{|c|}{ Time } & \multicolumn{1}{c|}{ Session } \\
\hline $03.30-05.00$ a.m. & Wake-up and Walking Meditation \\
\hline $05.00-06.30$ a.m. & Sitting Meditation \\
\hline $06.30-08.15$ a.m. & Breakfast dana and Lay responsibilities* \\
\hline $08.15-09.15$ a.m. & Sitting Meditation \\
\hline $09.15-10.15$ a.m. & Walking Meditation \\
\hline $10.15-11.15$ a.m. & Sitting Meditation \\
\hline $11.15-12.00$ p.m. & Lunch Daana \\
\hline $12.00-01.00$ p.m. & Walking Meditation \\
\hline $01.00-02.00$ p.m. & Q\&A / Dhamma Discussion (Every Day) \\
\hline $02.00-03.00$ p.m. & Walking Meditation \\
\hline $03.00-04.00$ p.m. & Sitting Meditation (Except the Last Day) \\
\hline $04.00-05.00$ p.m. & Walking Meditation \\
\hline $05.00-06.30$ p.m. & Dhamma Talk (Except the Last Day) \\
\hline $06.30-07.00$ p.m. & Mindfullness Gilanpasa Break \\
\hline $07.00-08.00$ p.m. & Walking Meditation \\
\hline $08.00-09.00$ p.m. & Sitting Meditation \\
\hline 09.00 p.m. & End of Day's Program \\
\hline
\end{tabular}




\subsection{PROBLEM STATEMENT}

Religious and cultural tourism is an important element of the tourism industry in Sri Lanka. Sri Lanka is a land of spirituality blessed with many places of non-secular and spiritual monuments etc. According to Sri Lanka's Annual Statistical Report on Tourism Development (SLTDA), the percentage of tourist visits for religious and cultural purposes in Sri Lanka was lower than 2006 to 2018. The highest percentage of tourist visits for religious purposes was $4.8 \%$ in 2013, while the percentage the lowest number of tourist visits for religious purposes was $0.00 \%$ in 2016.Because religious tourism in Sri Lanka has not received the necessary attention from the government, private sector and researchers.

Meditation, yoga and other religious activities are key elements of the Buddhist temple stay program and a solid foundation for inner peace. Therefore, it would be more beneficial to attract Buddhist and non-Buddhist tourists to Sri Lanka to develop a Buddhist temple stay program in Sri Lanka. Unfortunately, the relevant authorities paid little attention to the development of Buddhist temple stay programs in Sri Lanka. Hence, it is an unused tourist product in Sri Lanka.

Furthermore, the path for Buddhist temple stay programs in Sri Lanka is not fully explored and the deficiencies and problems are not properly assessed. Therefore, the purpose of study is specially focus on the current behavioral pattern of tourist of temple stay program and their perception about programs. And also, identify major challenges to develop temple stay programs in Sri Lanka will help to increase number of tourist visit to Sri Lanka for the purpose of religious and cultural tourism.

\subsection{OBJECTIVE OF STUDY}

i. To identify the current behavioral pattern of tourist who engaged with temple stay programs in Sri Lanka

ii. To examine tourist perception on Buddhist temple stay programs in Sri Lanka as a concept of tourism development.

iii. To identify the challenges facing by tourist while engage with Buddhist temple stay programs in Sri Lanka.

\subsection{LITERATURE REVIEW}

Perception can be defined as a series of internal sensational cognitive processes in the brain at the subconscious cognitive functional layer that recognize, connect, interpret and seek internal cognitive information in the mind (Wang, 2007). Tourist perceptions can be interpreted as tourists' opinions, both positive and negative about certain things (Fauziah \& Fathiah, 2011). It's also talked about tourists with their previous experiences (Rajaratnam et al., 2015). Ahadi et al(2015), perceptions of other tourists apart from tourist appreciation of certain things. Based on previous research, it can be concluded that tourists' perceptions can be interpreted as opinions about what tourists actually experience during the holidays.

The concept of temples stay program are widespread in many East Asian countries such as Japan, China, Thailand, Myanmar, India, Bhutan, Bangladesh and Nepal (Kaplan, 2010). In most countries, temple stays are governed by separate Buddhist temples or separate viewing areas. As a result, accommodation options, temple activities, infrastructure conditions, and road information may not be suitable or convenient to access.

Wei Wang, (2011). "Explore the Phenomenon of Buddhist Temple Stay in South Korea for Tourist", identified effecting key factors for Buddhist temple stay in South Korea for tourist.To get a better picture of the temple stay program and its implications, a large survey was conducted between October and December 2007 to examine the experiences and perceptions of visitors to the temple stay program. There are 360 questionnaires were collected from foreign visitors. Using and analyzing existing research data yields some interesting insights. According to the study, researchers found that there are three main reasons for attracting tourists to Korean temple stay programs. They are environmentally friendly, socially identifiable and economically viable.

Moneentr.T and Ha Tran. T (2014), "SWOT Analysis of Religious Tourism in Nong Khai Province, Thailand Proposed Guidelines to Incorporate Temple Stay Program" identified key strengths of developing religious tourism in Nong Khai Province, Thailand. These are various religious activities, public transportation, interest group collaboration, many temples, many famous monks, famous traditional festivals, the power of Buddhism, many festival days involving Buddhism, etc. In order to understand this information, researcher use the primary resource for his research. So they chose Nong Khai Province to pick their data. The main informants are ten people. There are monks belonging to government organizations, tourism entrepreneurs, and local philosophers who work at temples and religious tourism destinations in Nong Kai Province. And also. Semi-structured interviews were conducted to collect data from key informants. Content analysis was used to identify data items and matrix tables were used to analyze qualitative data.

According to Choe at el. (2013), there is a significant correlation between the likelihood of visitors visiting Buddhist temples and the intellectual dimension and avoidance of stimuli from the leisure time motivation scale. In addition, women score higher than men in terms of avoiding incentives. These results indicate the motivation of tourists to visit Buddhist temples and can be of benefit to tourism officials who promote Buddhist temples. In 
addition, the results indicate the importance of the potential visitor's psychological needs, such as "running away" or "unusual". In this study, these reasons included travel motivated by the goal of brain enrichment and the need to seek a calm and serene environment that induces relaxation. The results impress those who offer sacred sights and provide them with information on how to commission their promotional materials to guide potential travelers effectively. For example, a visitor might want to learn new things, the calm and relaxed aspects of visiting a Buddhist temple. Additional opportunities to tackle visitor intellectual development and relaxation include programs such as tea ceremonies, yoga, meditation and zen classes, as well as seminars on Buddhism, martial arts and traditional games.

\subsection{Motivation theories for tourist on Temple stay Programs}

There are different types of motivation theories. I have selected the best-known related theories about the remaining Buddhist temple stay programs and summarize them here.

\subsubsection{Push and Pull theory for temple stay programs}

According to the push and pull theory, the concept of push and pull can explain why people participate in programs organized by Buddhist temples (Fig. 4.1). The concept of push refers to the fact that a person wants to participate in a religious program to fulfill a need. The concept of pull refers to the fact that a place is designed in such a way that its property attracts tourists.

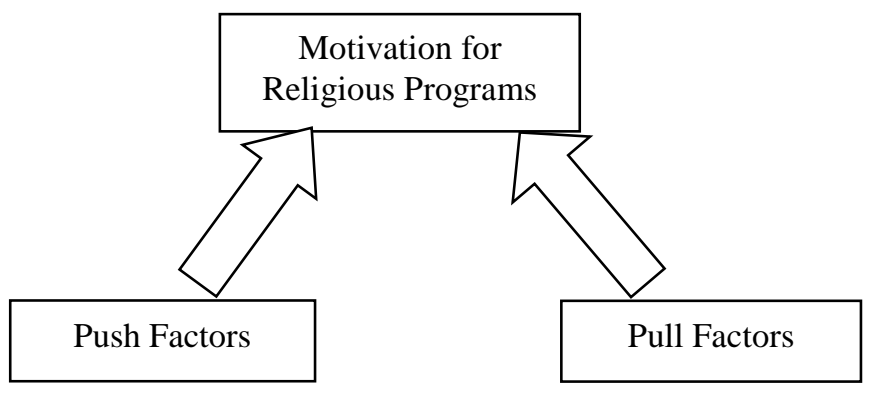

Fig. 4.1: Push and pull theory (Source: Gnoth.J, 1977)

4.1.2 The Sunlust and Wanderlust theory for temple stay programs

The concept of the sun and wanderlust can illustrate why people engage with temple programs (Fig. 4.2). The concept of sunlust explains the fact that tourists are attracted to places that offer special facilities that do not exist in their own place of residence. The term wanderlust describes the desire of tourists to go from one place to another.

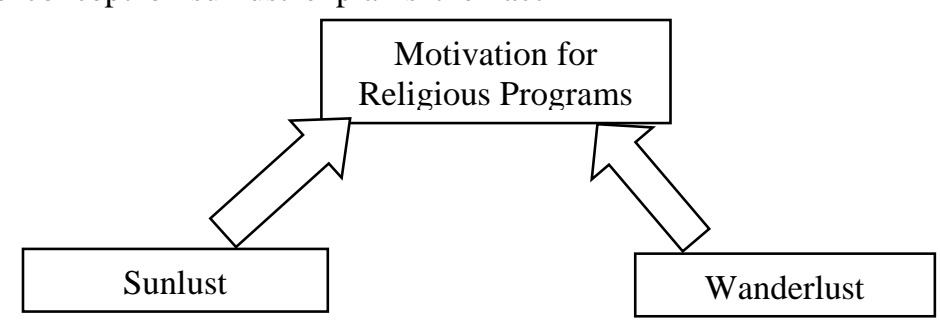

Fig. 4.2: sunlust and wanderlust theory (Source: Tsephe.N.P, and Obono.S.D, 2013).

\subsection{Maslows Theory on Temple Stay Programs}

Maslow's five-level hierarchy of needs theory (Fig.4.3) has gained widespread acceptance and is used to explain travel behavior. Furthermore, the satisfaction and perception of visitor needs is an important when developing a temple stay program in Sri Lanka. 


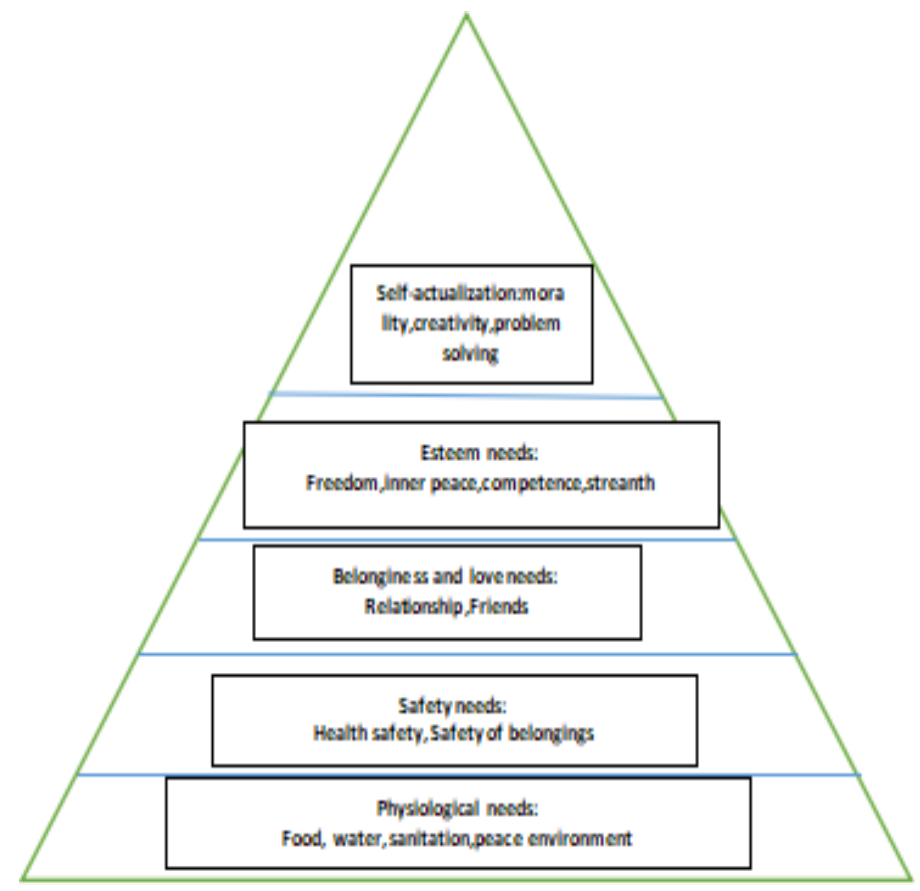

Fig. 4.3:Maslow's Theory of Motivation.(Source: Maslow, A. H ,1954)

1-Physiological needs: - in this level of hierarchy people must be satisfied their physiological need in temples which involves basic survival needs such as the needs of air, water, food,sanitation, peace environment and basic accomodation. People cannot be concerned with any higher-order wants until they have satisfied their basic requirements.

2-Safety needs: - this level is the second level of maslow; hierarchy of needs which concerns people's need to be secure and safe in their environment of the temple. It involves the need for psychological and physical safety.

3-Belongingness and love need: - these needs include dealing with and acceptance by service provider of the temple, giving and receiving affection and friendship . Based on Maslow's theory people can't achieve to this level until satisfied their physiological and safety needs.

4-Esteem needs: - according to Maslow theses needs may be classified in to two subsidiary setsin temple stay programs. First, the desire for achievement, adequacy, strength, competence, inner peace and freedom.Seconde we have what we may call the desire for reputation or prestige, status, recognition importance and dignity.

5-Self actualization needs: - The final stage in the linear growth of an individual after the engage with temple stay programs. Maslow believed that in order to achieve this state of personal fulfilment such as morality,creativity,problem solving and lack of prejudice,etc, the person must first satisfy the preceding needs (i.e. physiological, safety, love/belonging, and esteem, in that order).

\subsection{METHODOLOGY}

In this study, an attempt was made to examine tourists' perceptions of the temple stay program in Sri Lanka. This study conducted with spiritual tourist who visited in meditation centers. Primary data from this study were collected using a structured questionnaire from 80 local and foreign tourists who visited Kandy, Gampaha and Badulla district meditation centres in Sri Lanka. The target groups are men and women over 20 years of age in the period from October to the end of December 2020. Convenience and judgemental sampling technique used for data collections.Both open and close-ended questions were used, the major source for information was the qualitative tool of in-depth interviews with tourists. The tourists' reviews after their post-visit to temples were analysed in order to interpret their perceptions and identify the theme for the study. Secondary data sources such as previous studies were the most significant used in this study;books, journals, reports, magazines and online data sources. The simple statistical analyses like demographic details and other patterns can be performed using the MS Excel software. But, in the over all results from the interviews of each participants will discuss with providing suitable recommendations to develop temple stay program in Sri Lanka.

\subsection{Social Economic Background of Respondents}

A completed demographic profile of the respondents was collected during the data collection period and summarized in table 5.1. the sample is relatively balanced between genders. Men comprise 55 percent of sample and female comprise 45 percent 
of sample.The majority of respondents $(38.75 \%)$ are between the ages 31 to 40 . The majority of respondents $(71.25 \%)$ are from other countries followed by France and Britain. The respondents are well educated. The majority of respondents $(42.5 \%)$ are university graduates followed by college graduates $(26.25 \%)$ and masters and above $(18.75 \%)$. The majority of respondents $(61.11 \%)$ are in middle income between \$1001- \$ 3000 per month. There are $20.83 \%$ respondents are in less than $\$ 1000$ income per month. The minority of the respondents (12.5\%) monthly income is between above $\$ 5000$.
A considerable number (40\%) of respondents are in other categories followed by businessmen and government sector. The majority of the respondents $(43.75 \%)$ are single followed by married $(30 \%)$ and divorced $(18.75 \%)$.The majority of the respondents $(47.22 \%)$ are spending less than \$ 50 per month in Sri Lanka.And also, here $30.55 \%$ respondents' monthly spending power is $\$ 51$ to $\$ 75$ in Sri Lanka.All the respondents are willing to revisit and engage with temple stay programs in Sri Lanka in the future.

Table 5.1: profile of tourists who are engaged with temple stay programs in Sri Lanka

\begin{tabular}{|l|l|l|l|l|l|}
\hline Variables & $\mathbf{N}$ & $\mathbf{\%}$ & Variables & $\mathbf{N}$ & $\mathbf{\%}$ \\
\hline Country of Residence & $\mathbf{8 0}$ & $\mathbf{1 0 0}$ & Marital Status & $\mathbf{8 0}$ & $\mathbf{1 0 0}$ \\
France & 10 & 12.5 & Single & 35 & 43.75 \\
USA & 05 & 6.25 & Married & 24 & 30.00 \\
Britain & 08 & 10 & Divorced & 15 & 18.75 \\
Other & 57 & 71.25 & Living together & 06 & 7.5 \\
\hline Sex & $\mathbf{8 0}$ & $\mathbf{1 0 0}$ & Average expenditure per day & $\mathbf{7 2}$ & $\mathbf{1 0 0}$ \\
Male & 44 & 55 & Below \$ 50 & 34 & 47.22 \\
Female & 36 & 45 & \$ 51- \$ 75 & 22 & 30.55 \\
& & & \$ 76-\$100 & 12 & 16.67 \\
& & & Over \$ 100 & 04 & 5.56 \\
\hline Age Group & $\mathbf{8 0}$ & $\mathbf{1 0 0}$ & Occupation & $\mathbf{8 0}$ & $\mathbf{1 0 0}$ \\
Below 20 & 2 & 2.5 & Student & 12 & 15 \\
$21-30$ & 18 & 22.5 & Businessmen & 22 & 27.5 \\
31-40 & 31 & 38.75 & Government sector & 14 & 17.5 \\
41-50 & 15 & 18.75 & Other & 32 & 40 \\
50 Above & 14 & 17.5 & & & \\
\hline Level of Education & $\mathbf{8 0}$ & $\mathbf{1 0 0}$ & Income Group (Per Month) & $\mathbf{7 2}$ & $\mathbf{1 0 0}$ \\
High School & 10 & 12.5 & Less than \$ 1000 & 15 & 20.83 \\
College graduate & 21 & 26.25 & \$ 1001- \$ 3000 & 44 & 61.11 \\
University graduate & 34 & 42.5 & \$3001-\$5000 & 12 & 16.67 \\
Masters \& above & 15 & 18.75 & Above \$ 5000 & 09 & 12.5 \\
\hline
\end{tabular}

Source: Survey data, 2020

5.2 Behavioural Patterns and over all Interpretations of Respondents : The questionnaire have been used to gather data for the behavioural patterns of respondents who are engaged temple stay programs in Sri Lanka

\subsubsection{Acquaintance of visit in respondents}

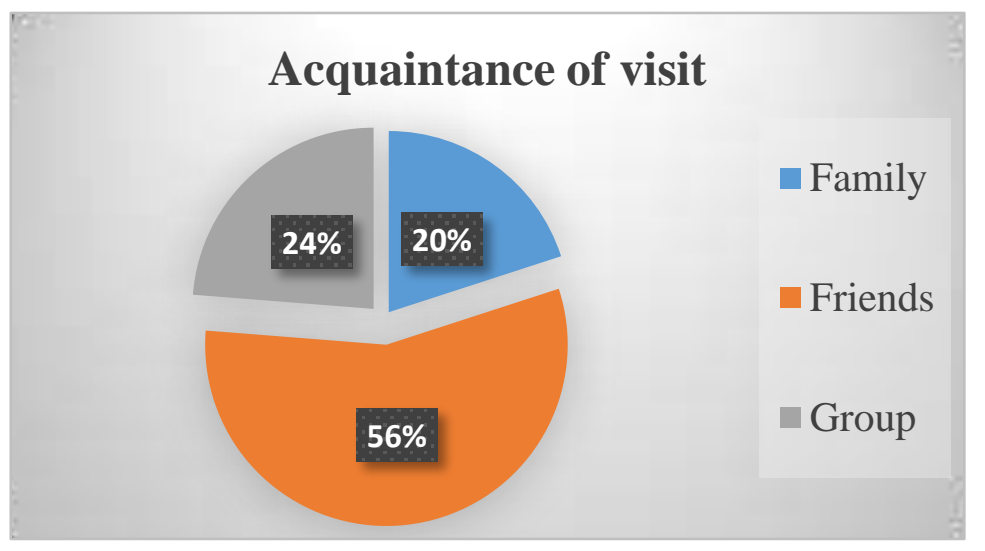

Source: Survey data,2020 
According to the figure 5.1.1, majority of the respondents $(56 \%)$ engaged temple stay program with their friends. And also, minority of the respondents $(20 \%)$ engaged with their families.

\section{5..1.2 Purpose of visit}

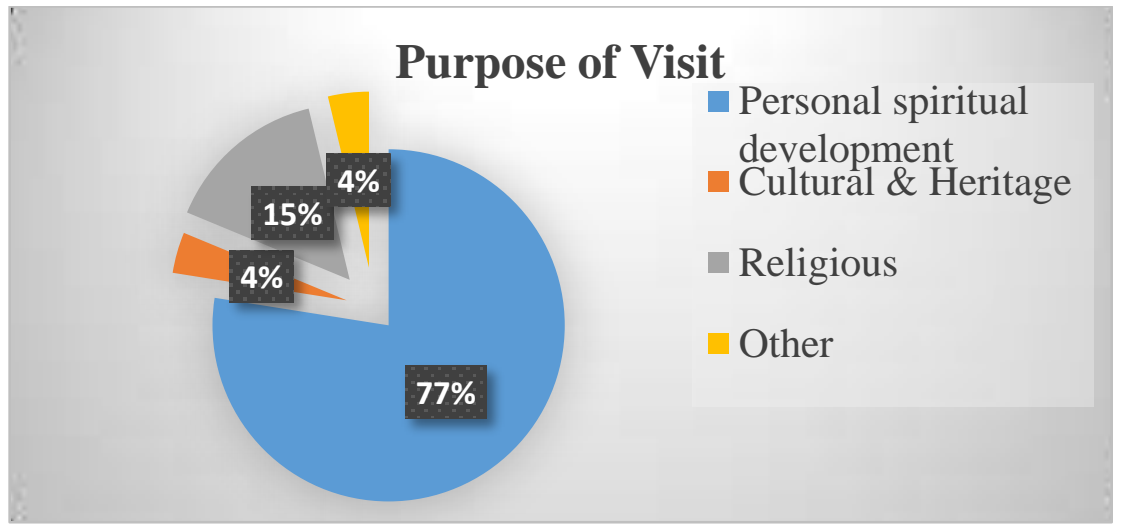

Source: Survey data,2020

According to the figure 5.1.2, majority of the respondents (77\%) engaged with temple stay program for their personal spiritual development. There are $15 \%$ of respondents engaged for religious purposes with their friends. And also, minority of the respondents (4\%) engaged for cultural and other purposes.

\subsubsection{Average stay of tourist}

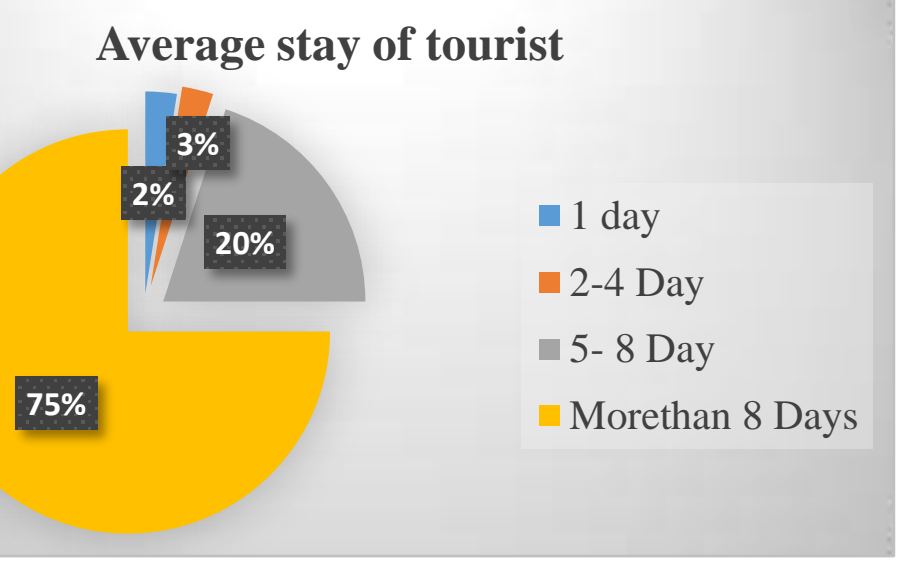

Source: survey data, 2020

According to the figure 5.1.3, majority of the respondents $(75 \%)$ usually stay more than 8 days in centres for temple stay programs. As well as, there is a $20 \%$ of respondents stay between 5 to 8 days. And also,minority of respondents $(2 \%)$ stay in one day for temple stay programs.

\subsubsection{Planning to visit again}

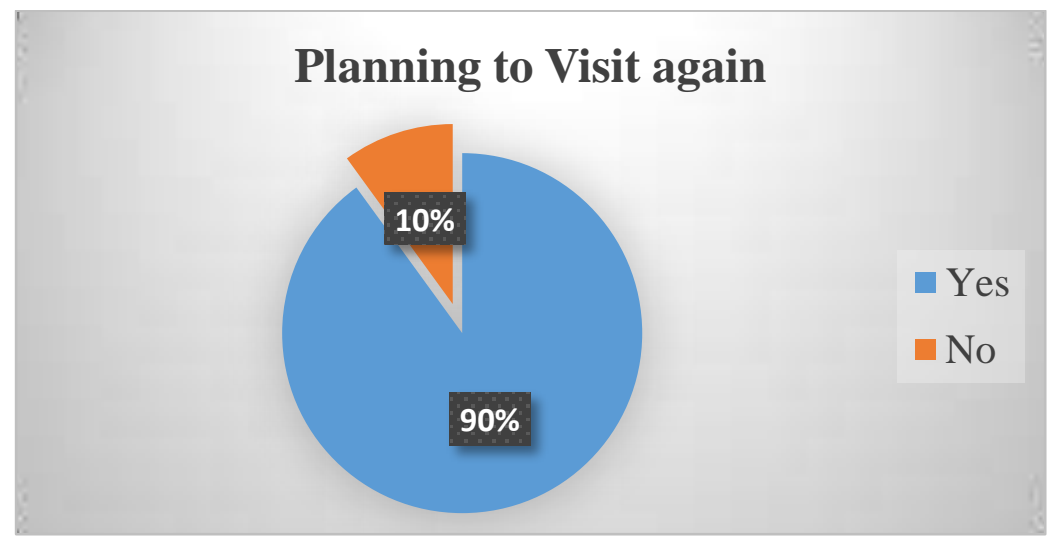

Source: Survey data, 2020 
According to the figure 5.1.5, majority of the respondents $(90 \%)$ are planning to visit again and engage with temple stay program in the future. The minority of respondents $(10 \%)$ are not planning to visit again in future, but they all satisied with temple stay programs conducted by venues.

\subsection{FINDING AND SUGGESTION}

In this section discuss the major finding of the research, with the tourist who are engaged with temple stay programs. It is divided into two small sections. Firstly,behavioral pattern and perception of tourist for better understanding of this research. Secondly,personal experience effects after the engage with temple stay programs such as satisfaction, changes etc.

\subsection{Behavioral pattern and perception of tourist about temple stay programs}

According to the simple statistical analysis of demographic details of tourist illustrate behavioral pattern of tourist who are engaged for temple stay programs in Sri Lanka. The majority of tourist more than eight days visited with their friends to the centres for the purpose of personal spiritual development. So, according to the services received from the centres, 90 percent of tourist satisfied with reality of program conducued by centres and planning to visit gain to the Sri Lanka.

According to the feed back of the tourist, infrastructure facilities, qualified human resources and community and service provider supports are an essential elements to revisit to the meditation centres in Sri Lanka. Because all meditation centres full fill with peaceful environment, rich appearance of the centres, attraction of surrounding areas,local foods, well knowledgeable human resources and an excellence of hospitality of local community and service providers. But, at present, there is some low level of accessibility to enter the temples. It is inconvenient to travel to centres, especially by car or public buses, because of the poor condition of the roads. Free independent travelers (FIT) are facing issues to reach the centres because of poor and lower level of accessibility. Accommodations another essential element, which is directly affecting to continue programme and satisfaction of their stay. Temporary stays in temples are also organized for either tourists or Buddhist practitioners with low level of facilities, but it has basic requirements for living. And also, Sanitation facilities are another complementary facility for the tourists. It should be more standard and need to make clean environment for users. Because sanitary facilities are directly affecting to continue their programme, safety and security and gust satisfaction.

According to the further findings, having with well qualified and knowledgeable trainers are positive fact for revisit to the spiritual tourist. But,
Majority of the respondents (54\%) the most challengable problem is language difficulties to select destination for meditation programmes. And also, lack of communication ability of trainers, are negative impact for delivering and understanding the technical knowledge to the participators. Therefore, it can overcome by organizing language training programmes or proper mechanism to communicate with trainers for better understandings of both parties.

As indicated by the further discoveries, first impression is most important factor in hospitality and tourism sector.Therefore, delightful welcome at airport is core motivational factor for tourists to visit to meditation centres and engage with programmes.That will be more beneficial for the sustenance of the spiritual tourism within the country and keep the tourist until end of the programme with their satisfaction. Local community attitudes and friendly support is another important complementary facility to persist for spiritual tourist. The quality of the hospitality services is highly expected by the tourists from the spiritual centres.Therefore, it is suggested that the government authorities should take necessary steps to enhance the quality of the hospitality services provided in meditation centres, Such as, organizing awareness programmes and explaining the value of tourism to local community for their economic development.

\subsection{Personal spiritual effects on temple stay programs}

According to the tourist point of view, there were not only physical improvements such as better position and flexibility, better general health condition, but also mental improvements such as better concentration, self-esteem and being more patience. Hence people distinctly recognize the overall health changes from meditation.Further discussion with tourist, they gave high scores for inner peace development and yoga practices. Thus, all of them were satisfied and they had positive experiences. Then for the result of recommendation, $100 \%$ of respondents wanted to recommend meditation to others. Thus, this result demonstrates how meditation is good and people recognized the value of meditation.

\subsection{CONCLUSION}

Temple stay program concept is unique and untapped tourism product in Sri Lanka.Meditation is the main component in temple stay program and its create an opotunity for spiritual tourist who seeks for inner peace of mind and scene of spiritual satisfaction. On the basis of result of this study, it can be conclude that several recommendations are needed to concern spiritual tourist's perception on temple stay program in Sri Lanka. This study has discovered that three factors (community \& service provider's support,qualified human resources and infrastructure 
facilities) and have a positive strong relationship with the meditation programs in Sri Lanka. The findings of this study can be helpful to planners, venue operators and marketers to develop strategies as to maintain standards and improve temple stay programs in Sri Lanka. In other words, they should focus on influencing factors that contribute to the overall satisfaction of spiritual tourists who are engaged with temple stay programs in Sri Lanka. Thus, this study helped to identify the importance of destination factors as perceived by the tourists who engaged with temple stay programs in Sri Lanka .

\subsection{REFERENCES}

1. Agrawal, M., Chaoudhary, H., \& Thripathi, G. (2010). Enhancing Buddhist tourism in India: An exploratory study. Worldwide Hospitality and Tourism Themes, 2(5), 477-493.

2. Anderson, B. J. (2005). Temple stay: Experience Buddhist temple culture to open up your Annual Statistical Report(Rep. No. 2016). (n.d.). Retrieved

http://www.sltda.lk/sites/default/files/annual-stati cal-report-2016.pdf Asian Studies, Singapore, pp. 51-61.

3. Choe, J., Blazey, M. \& Mitas, O. (2013). Motivations of non-Buddhists visiting Buddhist Temples. Current Issues in Tourism. DOI:10.1080/13683500.2013.771627.

4. Chopra, D., \& Simon, D. (2004). The seven spiritual laws of yoga. A practical guide to healing body, mind and spirit. Wiley \& Sons, Inc: New Jersey.

5. Crompton, J. L. (1979). Motivations for pleasure vacation. Annals of Tourism Research, 6(4), 408-424. http://dx.doi.org/10.1016/0160-7383(79)90004-5

6. DESILVIA, L. A Buddhism: Beliefs and practices in Sri Lanka. Colombo: Author, 1974.

7. Duarah, I \& Bhaskar. (2013). Tourism Potentiality in North East India", International Journal of Science and Research, Vol. 2, No.10, pp. 1-3. 